\title{
Pharmacokinetic study of isoquercitrin in rat plasma after intravenous administration at three different doses
}

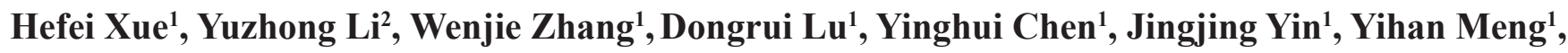 \\ Xixiang Ying ${ }^{1, *}$, Tingguo Kang ${ }^{1}$
}

${ }^{1}$ School of Pharmacy, Liaoning University of Traditional Chinese Medicine, Dalian, China, ${ }^{2}$ Department of Inspection, Second Affiliated Hospital of Dalian Medical University, China

\begin{abstract}
The aim of this study is to develop a simple and specific HPLC method using vitexin as the internal standard to investigate the pharmacokinetics of isoquercitrin (ISOQ) after three different doses administrated intravenously to rats. The pharmacokinetic parameters were calculated by both compartmental and non-compartmental approaches. The results showed that ISOQ fitted a three-compartment open model. The values of AUC increased proportionally within the range of $5-10 \mathrm{mg} \cdot \mathrm{kg}^{-1}$. Moreover, $\alpha$ half-life, $\beta$ half-life, ${ }^{\mathrm{a}} \mathrm{CL}, \mathrm{MRT}_{0-\mathrm{t}}$ and MRT ${ }_{0 \rightarrow \infty}$ of ISOQ in rats showed significant differences between $20 \mathrm{mg} \cdot \mathrm{kg}^{-1}$ and other doses, indicating that ISOQ presented dose-dependent pharmacokinetics in the range of 5-10 $\mathrm{mg} \cdot \mathrm{kg}^{-1}$ and non-linear pharmacokinetics at higher doses.
\end{abstract}

Uniterms: Isoquercitrin/pharmacokinetics/experimental study. High Performance Liquid Chromatography. Crataegus pinnatifida Bge. Var major/leaves/phytochemistry.

\begin{abstract}
O objetivo deste estudo é desenvolver um método simples e específico de HPLC usando vitexina como padrão interno para investigar a farmacocinética do isoquercitrina (ISOQ) após três doses diferentes administradas por via intravenosa a ratos. Os parâmetros farmacocinéticos foram calculados pelas abordagens compartimental e não compartimental. Os resultados mostraram que ISOQ se encaixa no modelo de três compartimentos. Os valores de AUC aumentaram proporcionalmente na faixa de $5-10 \mathrm{mg} \cdot \mathrm{kg}^{-1}$. Além disso, $\alpha$ meia-vida, $\beta$ meia-vida, ${ }^{\mathrm{a}} \mathrm{CL}, \mathrm{MRT}_{0-\mathrm{t}}$ and $\mathrm{MRT}_{0 \rightarrow \infty}$ de ISOQ em ratos mostraram diferenças significativas entre $20 \mathrm{mg} \cdot \mathrm{kg}^{-1}$ e outras doses, o que significa que ISOQ apresenta farmacocinética dose-dependente no intervalo de $5-10 \mathrm{mg} \cdot \mathrm{kg}^{-1}$ e farmacocinética não linear em doses mais elevadas.
\end{abstract}

Unitermos: Isoquercitrina/farmacocinética/estudo experimental. Cromatografia líquida de alta eficiência. Folhas de Crataegus pinnatifida Bge. Var major/folhas/fitoquímica.

\section{INTRODUCTION}

The leaves of Crataegus pinnatifida Bge. var. major recorded in the Chinese Pharmacopoeia are a well-known traditional Chinese medicine and contain many compounds such as chlorogenic acid, vitexin-4"$O$-glucoside, vitexin-2"-O-rhamnoside, vitexin, rutin, hyperoside, isoquercitrin (ISOQ), and quercetin (Ying et al., 2009). In recent years, ISOQ, a flavonol glycoside, has attracted a great deal of attention because of its numerous

\footnotetext{
*Correspondence: Xixiang Ying. School of Pharmacy, Liaoning University of Traditional Chinese Medicine, 77 Shengming 1 Road, DD Port, 116600 - Dalian, China. E-mail: yingxixiang@163.com
}

biological and pharmacological activities, including antiinflammatory activity (Rogerio et al., 2007), antioxidant activity in vitro and in vivo (Silva et al., 2009), being effective at attenuating the death of RGC-5 cells in culture caused by exposure to hydrogen peroxide $\left(\mathrm{H}_{2} \mathrm{O}_{2}\right)$, and treating glaucoma (Jung et al., 2010). Moreover, many methods including HPLC-UV (Bramati, Aquilano, Pietta, 2003), LC-DAD and LC-MS (Maria et al., 2007), CZE-UV (Jing et al., 2007), SPE-HPLC (Lai et al., 2007) have been reported in the literature for the quantification of ISOQ in various herbal medicines. Also, in vitro and in vivo analyses of ISOQ have been reported (Chang et al., 2005). However, there was little attention paid to the pharmacokinetic study of ISOQ after intravenous 
administration at three different doses, and therefore the aim of this study is to investigate the pharmacokinetics of ISOQ employing a validated HPLC method with an internal standard (I.S.). To the best of our knowledge, this is the first report of a pharmacokinetic study following the intravenous administration of ISOQ in rats at multiple doses.

\section{MATERIAL AND METHOD}

\section{Reagents and chemicals}

ISOQ and the internal standard, vitexin, were both isolated from leaves of C. pinnatifida Bge. var major in our laboratory; the purities of both were found to be over $98 \%$ by HPLC analysis. The leaves were collected in Shenyang, Liaoning Province, China and identified by Prof. Bing Wang. Voucher specimens (20111020) were maintained at the Liaoning University of Tradition Chinese Medicine. The chemical structures of ISOQ and vitexin, confirmed by ${ }^{1} \mathrm{H}$ and ${ }^{13} \mathrm{C}$-nuclear magnetic resonance spectroscopy, are shown in Figure 1.
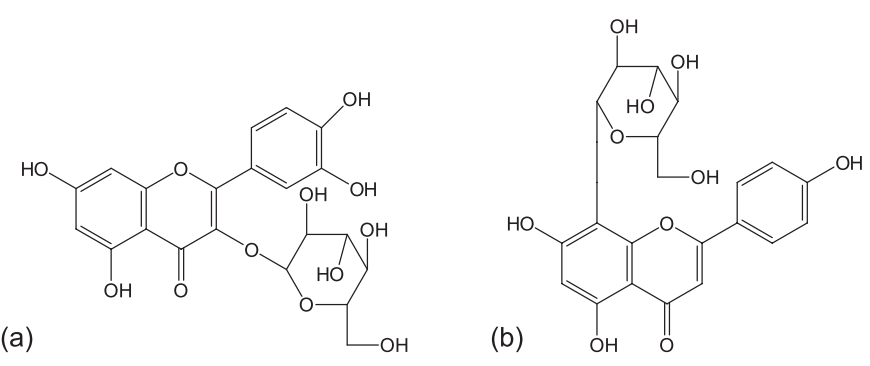

FIGURE 1 - Chemical structures of isoquercitrin (a) and vitexin (b).

The water used in all experiments was purified by a Milli-Q® Biocel Ultrapure Water System (Millipore, Bedford, MA, USA). Methanol and acetonitrile were both of HPLC grade and purchased from Damao (Chemical Reagent Plant, Tianjin, China). All other reagents were of analytical grade (Jinfeng Chemical Factory, Tianjin, China).

\section{Isolation and identification}

A sample $(5 \mathrm{~kg})$ of the leaves of $C$. pinnatifida Bge. var major was extracted twice using $50 \mathrm{~L}$ of $60 \%$ aqueous ethanol each time. The crude extract was concentrated and then passed through a porous-polymer resin (AB-8, Tianjin, China). The fraction eluted with $70 \%$ ethanol was evaporated under reduced pressure to obtain an extract and subjected to silica-gel column chromatography eluted with ethyl acetate:butanone:formic acid:water $(6: 2: 1: 0.2)$. Fractions of similar composition pooled on the basis of TLC analysis (UV monitoring at $365 \mathrm{~nm}$ ) were repeatedly subjected to silica gel column chromatography and sublimated on a Sephadex LH-20 column to obtain $0.6 \mathrm{~g}$ of ISOQ with a purity of $98 \%$, which was checked by HPLC. The chemical structures of ISOQ confirmed by ${ }^{1} \mathrm{HNMR},{ }^{13} \mathrm{CNMR}$ and MS data were consistent with previous reports (Zhang, $\mathrm{Xu}, 2001$; Wang et al., 2004).

\section{Chromatographic system}

The analyses were carried out on an Agilent 1100 series HPLC system (Agilent Technology, Palo Alto, CA, USA) which consisted of a quaternary pump (G1310A), a vacuum degasser (G1322A), a UV-visible spectrophotometric detector (G1314A) and Chemstation software (Agilent). The analytes were determined at $30^{\circ} \mathrm{C}$, kept by a column heater (Replete technology, Dalian), on an analytical Diamonsil $\mathrm{C}_{18}$ column $(150 \mathrm{~mm} \times 4.6 \mathrm{~mm}$ i.d., $5 \mu \mathrm{m}$, Diamonsil, USA) protected by a $\mathrm{KR} \mathrm{C}_{18}$ guard column $(35 \mathrm{~mm} \times 8.0 \mathrm{~mm}$, i.d., $5 \mu \mathrm{m}$, Dalian Create Science and Technology Co., Ltd., China). The mobile phase, which consisted of methanol-acetonitrile- $0.1 \%$ aqueous formic acid $(35: 5: 60, \mathrm{v} / \mathrm{v} / \mathrm{v})$, was filtered and degassed under reduced pressure before use. All chromatographic measurements were performed at $30{ }^{\circ} \mathrm{C}$ and a flow rate of $1 \mathrm{~mL} \cdot \mathrm{min}^{-1}$ with the detection wavelength of $360 \mathrm{~nm}$.

\section{Plasma Sample Preparation}

$10 \mu \mathrm{L}$ of I.S. (vitexin, $22.6 \mu \mathrm{g} \cdot \mathrm{mL}^{-1}$ ), $10 \mu \mathrm{L}$ of acetic acid, and $500 \mu \mathrm{L}$ of methanol were successively pipetted into the $100 \mu \mathrm{L}$ plasma samples, followed by vortex mixing for $1 \mathrm{~min}$. The supernatant was separated and evaporated to dryness under a stream of nitrogen at $40{ }^{\circ} \mathrm{C}$ after being centrifuged at $890 \times g$ for $15 \mathrm{~min}$. The residue was constituted in $100 \mu \mathrm{L}$ of mobile phase and centrifuged at $15,092 \times g$ for $10 \mathrm{~min}$. A $20 \mu \mathrm{L}$ aliquot of each supernatant was analyzed by HPLC.

\section{METHOD VALIDATION}

\section{Selectivity}

Selectivity was shown by comparing chromatograms of blank plasma obtained from rats prior to dosing with those of corresponding standard plasma samples spiked 
with ISOQ and I.S., and plasma samples from rats after the intravenous administration of ISOQ.

\section{Preparation of standards and quality control samples}

Standard stock solutions of ISOQ and I.S. were prepared in methanol to yield the concentrations of 160 and $226 \mu \mathrm{g} \cdot \mathrm{mL}^{-1}$, respectively. The working solutions were prepared with diluted stock solution to concentrations over the range of $0.4-160 \mu \mathrm{g} \cdot \mathrm{mL}^{-1}$. All working solutions were stored at $4^{\circ} \mathrm{C}$. Seven calibrators $(0.2,0.4,0.8,2,5$, 20 and $80 \mu \mathrm{g} \cdot \mathrm{mL}^{-1}$ ) of ISOQ were prepared by adding standard working solutions $(50 \mu \mathrm{L})$ and the working solution I.S. $\left(22.6 \mu \mathrm{g} \cdot \mathrm{mL}^{-1}, 10 \mu \mathrm{L}\right)$ to drug-free rat plasma. The quality control (QC) samples were prepared at low $\left(0.6 \mu \mathrm{g} \cdot \mathrm{mL}^{-1}, 3\right.$ times of the lower limit of quantitation), high $\left(60 \mu \mathrm{g} \cdot \mathrm{mL}^{-1}, 75 \%\right.$ of the upper limit of quantitation) and medium $\left(6 \mu \mathrm{g} \cdot \mathrm{mL}^{-1}\right.$, near the geometric mean of low and high concentration) concentrations in bulk and aliquots were stored at $-20{ }^{\circ} \mathrm{C}$ prior to analysis.

\section{Linearity and LOD}

The linearity was evaluated over the concentration range of $0.2-80 \mu \mathrm{g} \cdot \mathrm{mL}^{-1}$ at seven levels of ISOQ. The calibration curves for ISOQ in plasma were generated by plotting the peak area ratio of ISOQ to I.S. versus the nominal concentrations in the standard plasma samples. The regression equation was obtained by weighted $\left(1 / \mathrm{c}^{2}\right)$ least square linear regression. The limit of detection(LOD) was determined by a signal-to-noise ratio of 3 . The lower limit of quantification (LLOQ) was defined as the lowest concentration of ISOQ in the calibration curves, giving an acceptable accuracy (R.E.) within $\pm 20 \%$ and a precision (R.S.D.) that did not exceed $20 \%$.

\section{Precision and accuracy}

The accuracy and precision of the method were evaluated with QC samples at three concentrations and using five replicates on three consecutive days. The intraand inter-assay precisions were assessed by determining the quality control samples at three concentration levels of $\operatorname{ISOQ}\left(0.6,6\right.$ and $\left.60 \mu \mathrm{g} \cdot \mathrm{mL}^{-1}\right)$. For the intra-day validation, five replicates of the QC plasma samples were analyzed on the same day. For the inter-day validation, five replicates of the QC plasma samples were analyzed on three different days. The precision was expressed as the R.S.D. which should be less than $15 \%$, except at the LLOQ where it should not exceed $20 \%$; the accuracy of the assay was determined by comparing the means of the determined ISOQ concentrations with the nominal concentrations. The mean percentage deviation from the nominal values was expressed as the R.E. which should be within $\pm 15 \%$ of the nominal value, except at the lower limit of quantification where it should not exceed $\pm 20 \%$.

\section{Extraction recovery}

The extraction efficiency was determined by comparing the peak areas of ISOQ from a blank plasma with a known concentration added with the peak areas of a blank plasma with the same concentration of ISOQ added after protein precipitation $(n=6)$.

\section{Stability}

Five aliquots of unextracted QC samples at low, medium and high concentrations were subjected to the conditions below. A short-term stability experiment was carried out at ambient temperature $\left(25^{\circ} \mathrm{C}\right)$ for $24 \mathrm{~h}$ and long-term stability was tested by storage at $-20^{\circ} \mathrm{C}$ for one month. QC samples were subjected three freeze $\left(-20^{\circ} \mathrm{C}\right)$-thaw (room temperature) cycles for determining freeze-thaw stability. Then, the samples were processed and analyzed. The concentrations obtained were compared with the nominal values of QC samples.

\section{Animals and pharmacokinetic study}

Male Wistar rats (weight $250 \pm 20 \mathrm{~g}$ ) were obtain from the Laboratory Animal Center of Liaoning University of Traditional Chinese Medicine (Shenyang, China). Before the experiments, all rats were kept in a controlled environment for one week and had free access to standard laboratory food and water. The rats were fasted 12-16 h prior to administration of the ISOQ. All animal studies were performed according to the Guidelines for the Care and Use of Laboratory Animals, which was approved by the Committee of Ethics of Animal Experimentation of Liaoning University of Traditional Chinese Medicine.

Three groups (five rats/group) were randomly assigned to receive ISOQ solution via a tail vein injection at doses of 5, 10 and $20 \mathrm{mg} \cdot \mathrm{kg}^{-1}$, respectively. ISOQ was dissolved in normal saline containing $20 \%$ propylene glycol-water $(\mathrm{v} / \mathrm{v})$. Blood samples $(0.3 \mathrm{~mL})$ were collected into heparinized tubes from the vena orbitalis at times of $2,5,10,15,20,30,45,60,90,120$ and 180 min after intravenous administration and then centrifuged at $890 \times g$ for $15 \mathrm{~min}$. The obtained plasma was stored at $-20^{\circ} \mathrm{C}$ until analysis. 


\section{RESULTS AND DISCUSSION}

\section{Method development}

To obtain suitable retention time and good separation for the analysis, many mixed solutions were used as the mobile phase, such as methanol-water $(40: 60,45: 55)$ and methanol-acetonitrile-water (30:5:65, 35:5:60, 25:10:65); $0.1 \%$ formic acid was added in the solvent system after numerous trials to improve the peak shape and resolution. A mixture of methanol-acetonitrile- $0.1 \%$ aqueous formic acid $(35: 5: 60, \mathrm{v} / \mathrm{v} / \mathrm{v})$ was finally selected for use in this study.

The UV absorption spectra of ISOQ have two maximum absorptions at $256 \mathrm{~nm}$ and $358 \mathrm{~nm}$ and that of I.S. at 269 and $331 \mathrm{~nm}$. The interferences from endogenous substances in the plasma were observed when the wavelength was set at $256 \mathrm{~nm}$; therefore, the detection wavelength was set at $360 \mathrm{~nm}$ because of no interference appeared and it was found to be suitable for the analysis of ISOQ and I.S.

A suitable internal standard should be similar to the analyte, ISOQ, either structurally or chemically. Hence, vitexin-4"'O-glucoside, vitexin-2"'-O-rhamnoside, hyperoside and vitexin were considered as the internal standards, with vitexin finally being chosen as the internal standard because the optimum resolution and retention time could be obtained when compared with analyte.

To simultaneously acquire high extraction recovery and precision of ISOQ and I.S., several solvents such as acetonitrile and methanol were applied to precipitate protein in different ratios during the preliminary investigation; the highest recovery occurred using $500 \mu \mathrm{L}$ of methanol. 10, 20 and $30 \mu \mathrm{L}$ of acetic acid were added to the plasma to avoid dissociation of the analyte, and a good peak shape was finally obtained when $10 \mu \mathrm{L}$ of acetic acid was added to the plasma.

\section{Method validation}

\section{Selectivity}

To determine the selectivity of this method, blank rat plasma, plasma spiked with ISOQ and I.S. and plasma samples from rats after intravenous doses of ISOQ were analyzed; results are shown in Figure 2. The chromatograms showed that there were no interfering peaks in the region of the peaks of the analyte and I.S. The retention times of ISOQ and I.S. were approximately $6.8 \mathrm{~min}$ and $10.6 \mathrm{~min}$, respectively. The total run time was $15.0 \mathrm{~min}$. (a)

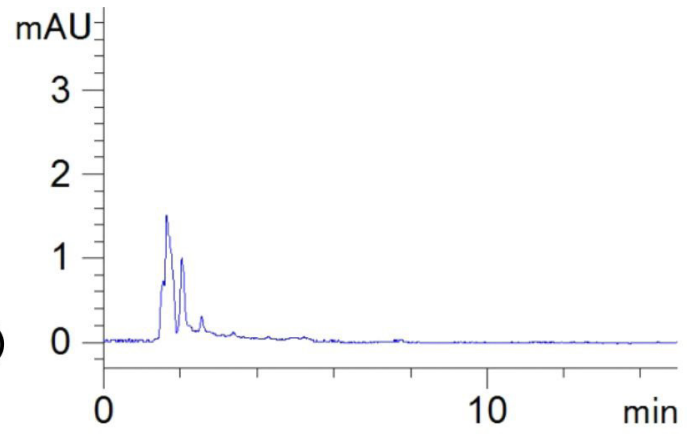

(b)

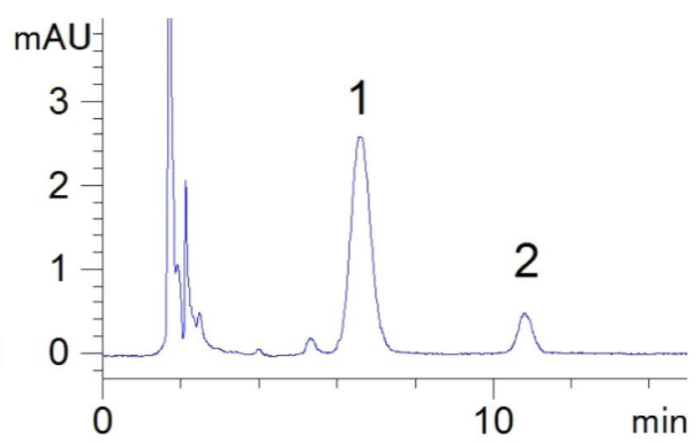

(c)

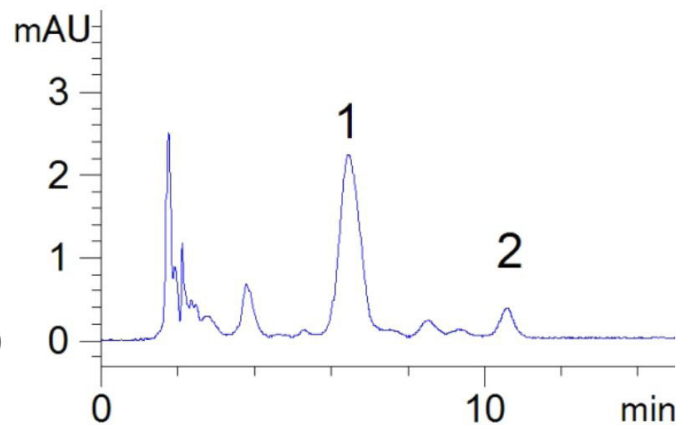

FIGURE 2 - Representative chromatograms of blank plasma (a), plasma spiked with isoquercitrin and vitexin (b) and plasma sample 60 min after the intravenous administration of isoquercitrin at a dose of $10 \mathrm{mg} \cdot \mathrm{kg}^{-1}$ (c). Peak 1: vitexin; Peak 2 : isoquercitrin.

\section{Calibration curve and quality control samples}

The evaluation of the linearity was performed with a seven-point calibration curve over the concentration range of $0.2-80 \mu \mathrm{g} \cdot \mathrm{mL}^{-1}$. The slope and intercept of the calibration graphs were calculated by weighted $\left(1 / \mathrm{c}^{2}\right)$ least squares linear regression. The regression equation of the calibration curves was typically: $y=0.2426 x-0.0242$, and $r$ was 0.9961 , where $y$ is the peak area ratio of ISOQ to I.S., and $x$ is the plasma concentration of ISOQ. The limit of detection (LOD) was $0.06 \mu \mathrm{g} \cdot \mathrm{mL}^{-1}$, which was determined by a signal-to-noise ratio $(\mathrm{S} / \mathrm{N})$ of 3 . The lower limit of quantification defined as the lowest concentration on the calibration curve, was $0.2 \mu \mathrm{g} \cdot \mathrm{mL}^{-1}$ with the precision and accuracy within $20 \%$, as verified by repeated analysis. 
TABLE I - Precision and accuracy of isoquercitrin determination in rat plasma (intra-day: $n=5$; inter-day: $n=3$ days with 5 replicates per day)

\begin{tabular}{|c|c|c|c|c|c|c|}
\hline \multirow{2}{*}{$\begin{array}{l}\text { Added conc. } \\
\left(\mu \mathrm{g} \cdot \mathrm{mL}^{-1}\right)\end{array}$} & \multicolumn{3}{|c|}{ Intra-day } & \multicolumn{3}{|c|}{ Inter-day } \\
\hline & $\begin{array}{c}\text { Conc. }\left(\mu \mathrm{g} \cdot \mathrm{mL}^{-1}\right) \\
(\mathrm{mean} \pm \mathrm{SD})\end{array}$ & R.S.D. (\%) & R.E. $(\%)$ & $\begin{array}{c}\text { Conc. }\left(\mu \mathrm{g} \cdot \mathrm{mL}^{-1}\right) \\
(\text { mean } \pm \mathrm{SD})\end{array}$ & R.S.D. (\%) & R.E. (\%) \\
\hline 0.6 & $0.642 \pm 0.046$ & 7.2 & 7.0 & $0.637 \pm 0.049$ & 7.7 & 6.2 \\
\hline 6 & $5.62 \pm 0.24$ & 4.2 & -6.3 & $6.27 \pm 0.46$ & 7.4 & 4.6 \\
\hline 60 & $62.2 \pm 1.4$ & 2.3 & 3.6 & $62.4 \pm 1.8$ & 2.8 & 4.0 \\
\hline
\end{tabular}

\section{Precision and accuracy}

The R.S.D.s and R.E.s for intra-day assay of three concentrations were in the ranges of 2.3 to $7.2 \%$ and -6.3 to $7.0 \%$, respectively, and that for inter-day were in the ranges of 2.8 to $7.7 \%$ and 4.0 to $6.2 \%$, respectively. The precision (R.S.D.) determined at each concentration level is required to not exceed $15 \%$ and accuracy (R.E.) was within $\pm 15 \%$ of the actual value which falls within the criteria for the analysis of biological samples according to the FDA(USFDA, 2001). The results are shown in Table I.

\section{Extraction recovery}

The extraction recoveries of ISOQ at three concentrations $\left(0.6,6\right.$ and $\left.60 \mu \mathrm{g} \cdot \mathrm{mL}^{-1}\right)$ were more than $91.24 \pm 6.93 \%$, and that of I.S. was $98.50 \pm 4.82 \%$, suggesting that there was negligible loss during extraction, which could be attributed to the high solubility of ISOQ in methanol and the one-step protein precipitation used in the sample preparation.

\section{Stability}

The short-term, long-term as well as freeze-thaw stabilities of ISOQ in plasma ranged from 92.73 to $99.85 \%$, indicating that no significant degradation occurred during chromatography, extraction and sample storage processes for ISOQ plasma samples.

\section{Pharmacokinetic study}

Pharmacokinetic data were processed by 3 p97 software (The Chinese Society of Mathematical Pharmacology, Beijing, China). The plasma concentrationtime curves of ISOQ in rats following intravenous injection of 5, 10 and $20 \mathrm{mg} \cdot \mathrm{kg}^{-1}$ body weight are shown in Figure 3; these demonstrate that ISOQ were eliminated rapidly from the plasma. The plasma concentrations of ISOQ were detectable only up to $0.75 \mathrm{~h}$ in rats at low dose, and $3 \mathrm{~h}$ in rats at high doses. The pharmacokinetic parameters were calculated by both compartmental and non-compartmental approaches; all pharmacokinetic parameters are given in Table II. The weight of $1 / \mathrm{c}^{2}$ was chosen by comparing the goodness of fit for 5, 10 and $20 \mathrm{mg} \cdot \mathrm{kg}^{-1}$. According to the F test, AIC and $\mathrm{R}^{2}$, a threecompartment open model gave the best fit to the plasma concentration-time curves obtained in rats. The values of AUC increased proportionally within the range of $5-10 \mathrm{mg} \cdot \mathrm{kg}^{-1}$. Additionally, the pharmacokinetic results of $\alpha$ half-life, $\beta$ half-life, ${ }^{\mathrm{a} C L}, \mathrm{MRT}_{0 \rightarrow \mathrm{t}}$ and $\mathrm{MRT}_{0 \rightarrow \infty}$ showed significant differences between $20 \mathrm{mg} \cdot \mathrm{kg}^{-1}$ and other doses. The $\alpha$ half-life at a dose of $20 \mathrm{mg} \cdot \mathrm{kg}^{-1}$ was more than those after other doses, indicating that the distribution of ISOQ in rats was slower at $20 \mathrm{mg} \cdot \mathrm{kg}^{-1}$. The greater $\beta$ half-life, MRT $_{0 \rightarrow \mathrm{t}}$ and $\mathrm{MRT}_{0 \rightarrow \infty}$ at $20 \mathrm{mg} \cdot \mathrm{kg}^{-1}$ suggested that ISOQ was subjected slower elimination than other doses. According to the above results, ISOQ presented dose-dependent pharmacokinetics in the range of $5-10 \mathrm{mg} \cdot \mathrm{kg}^{-1}$ and non-linear pharmacokinetics at higher

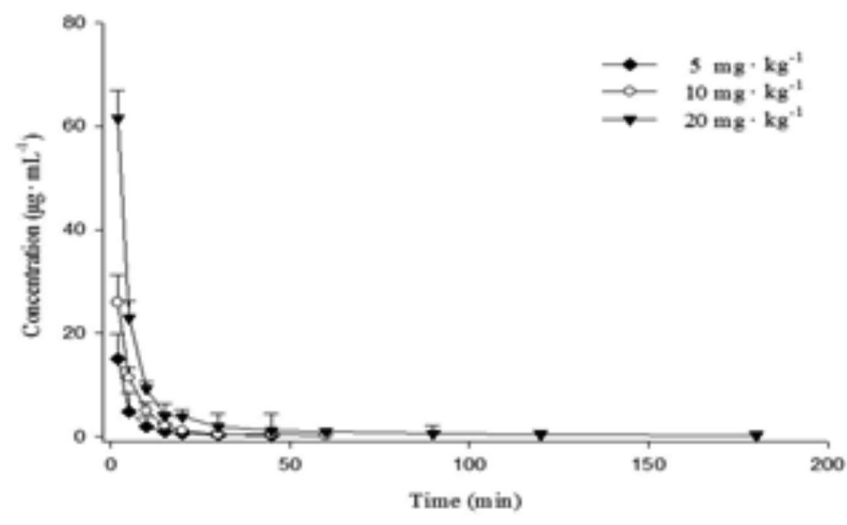

FIGURE 3 - Mean plasma concentration-time curves of isoquercitrin in rats (mean \pm S.D., $n=5$ ) after the intravenous administration of doses of 5, 10 and $20 \mathrm{mg} \cdot \mathrm{kg}^{-1}$. These sampling points, which could not be detected, i.e. plasma concentrations under the LOQ, were not included in the mean plasma concentration-time curves. 
TABLE II - Pharmacokinetic parameters of isoquercitrin in rats (mean \pm S.D., $n=5)$ after the intravenous administration of doses of 5,10 and $20 \mathrm{mg} \cdot \mathrm{kg}^{-1}$

\begin{tabular}{lccc}
\hline Dose $\left(\mathrm{mg} \cdot \mathrm{kg}^{-1}\right)$ & 5 & 10 & 20 \\
\hline $\mathrm{Vc}\left(\mathrm{L} \cdot \mathrm{kg}{ }^{-1}\right)$ & $0.142 \pm 0.03$ & $0.149 \pm 0.04$ & $0.170 \pm 0.03$ \\
$\mathrm{t}_{1 / 2 \alpha}(\mathrm{min})$ & $3.66 \pm 0.31$ & $3.65 \pm 0.25$ & $9.06 \pm 0.11^{*}$ \\
$\mathrm{t}_{1 / 2 \beta}(\mathrm{min})$ & $38.1 \pm 0.29$ & $39.9 \pm 0.67$ & $62.4 \pm 0.72^{*}$ \\
$\mathrm{AUC}_{0 \rightarrow \infty}{ }^{a}\left(\mathrm{mg} \cdot \mathrm{min} \cdot \mathrm{L}^{-1}\right)$ & $157.1 \pm 83.2$ & $366.5 \pm 79.5$ & $545.3 \pm 89.7$ \\
$\mathrm{CL}^{\mathrm{a}}\left(\mathrm{kg} \cdot \mathrm{L} \cdot \mathrm{min}{ }^{-1}\right)$ & $0.0436 \pm 0.0005$ & $0.0430 \pm 0.0008$ & $0.0366 \pm 0.0003^{*}$ \\
$\mathrm{MRT}_{0 \rightarrow \mathrm{t}}(\mathrm{min})$ & $6.75 \pm 0.32$ & $6.69 \pm 0.41$ & $18.7 \pm 0.37^{*}$ \\
$\mathrm{MRT}_{0 \rightarrow \infty}(\mathrm{min})$ & $9.30 \pm 0.45$ & $9.26 \pm 0.49$ & $27.1 \pm 0.98^{*}$ \\
$\mathrm{AUC}_{0 \rightarrow \mathrm{b}} \mathrm{b}\left(\mathrm{mg} \cdot \min \cdot \mathrm{L}^{-1}\right)$ & $107.2 \pm 63.2$ & $243.6 \pm 192$ & $494.6 \pm 222$ \\
$\mathrm{AUC}_{0 \rightarrow \infty} \mathrm{b}\left(\mathrm{mg} \cdot \min \cdot \mathrm{L}^{-1}\right)$ & $111.6 \pm 59.0$ & $250.5 \pm 203$ & $512.3 \pm 245$ \\
\hline
\end{tabular}

${ }_{\mathrm{a}, \mathrm{b}}^{\mathrm{b}}$ The compartmental and non-compartmental approach, respectively. $* \mathrm{P}<0.05$ by one-way ANOVA compared with 5 and $10 \mathrm{mg} \cdot \mathrm{kg}^{-1}$ dose of isoquercitrin.

doses, mainly because the metabolic enzyme of the drug or carrier of drug membrane-permeable process is saturated at high concentrations; i.e. the catalytic capability of metabolic enzymes or the transportation capability of a carrier is saturated when the dosage and the concentration in vivo exceed a certain limit (Leon, Andrew, 1993).

\section{CONCLUSIONS}

A simple and specific HPLC method was developed for the determination of ISOQ in rat plasma, which was successfully applied to an in vivo kinetic study in rats. ISOQ presented dose-dependent pharmacokinetics in the range of 5-10 $\mathrm{mg} \cdot \mathrm{kg}^{-1}$ and non-linear pharmacokinetics at higher doses. The validated method contributes not only to the determination of ISOQ in rat plasma but also to our understanding of the pharmacokinetic characteristics of ISOQ over the multiple doses in rats after intravenous administration.

\section{ACKNOWLEDGMENTS}

The study was supported by Shenyang Science and Technology Planning Project Foundation (F13-194-9-00), China.

\section{REFERENCES}

BRAMATI, L.; AQUILANO, F.; PIETTA, P. Unfermented rooibos tea: quantitative characterization of flavonoids by HPLC-UV and determination of the total antioxidant activity. J. Agric. Food Chem., v.51, p.7472-7474, 2003.
CHANG, Q.; ZUO, Z.; WALTER, K.K.H.; MOSES, S.S.C. Comparison of the pharmacokinetics of hawthorn phenolics in extract versus individual pure compound. J. Clin. Pharmacol., v.45, p.106-112, 2005.

GUIDANCE FOR INDUSTRY: bioanalytical method validation. In: U.S. Department of Health and Human Services. Food and Drug Administration, Center for Drug Evaluation And Research (CDER), Center for Biologics Evaluation And Research (CBER), 2001. Available at: $<$ www.fda.gov/downloads/Drugs/GuidanceCompliance RegulatoryInformation/Guidances/UCM070107.pdf.> . Accessed on: May 2001.

JING, R.J.; JIANG, X.Y.; HOU, S.R.; LI, X.J.; YUAN, Z.B. Determination of flavonoids in a citrus fruit extract by LCDAD and LC-MS. Food Chem., v.101, p.1742-1747, 2007.

JUNG, S.H.; KIM, B.J.; LEE, E.H.; OSBORNE, N.N. Isoquercitrin is the most effective antioxidant in the plant Thuja orientalis and able to counteract oxidativeinduced damage to a transformed cell line (RGC-5 cells). Neurochem. Int., v.57, p.713-721, 2010.

LAI, X.Y.; ZHAO, Y.Y.; LIANG, H.; BAI, Y.J.; WANG, B.; GUO, D. SPE-HPLC method for the determination of four flavonols in rat plasma and urine after oral administration of Abelmoschus manihot extract. J. Chromatogr. B Analyt. Technol. Biomed. Life. Sci., v.852, p.108-114, 2007.

LEON, S.; ANDREW, B.C.Y. Applied biopharmaceutics \& pharmacokinetics. London: Prentice-Hall Co., 1993. p.375-379. 
MARIA, L.M.B.; CRISTINA, A.L.; OLGA, J.; ROSA, M.L.R. Determination of quercetin, luteolin, daempferol and isoquercitrin in stamen nelumbinis by capillary zone electrophoresis-ultraviolet detection. Chinese J. Anal. Chem., v.35, p.1187, 2007.

ROGERIO, A.P.; KANASHIRO, A.; FONTANARI, C.; DA SILVA, E.V.G.; LUCISANO-VALIM, Y.M.; SOARES, E.G.; FACCIOLI, L.H. Anti-inflammatory activity of quercetin and isoquercitrin in experimental murine allergic asthma. Inflamm. Res., v.56, p.402-408, 2007.

SILVA, C.G.; RAULINO, R.J.; CERQUEIRA, D.M.; MANNARINO, S.C.; PEREIRA, M.D.; PANEK, A.D.; SILVA, J.F.M.; MENEZES, F.S.; ELEUTHERIO, E.C.A. In vitro and in vivo determination of antioxidant activity and mode of action of isoquercitrin and Hyptis fasciculata. Phytomedicine, v.16, p.761-767, 2009.
WANG, X.R.; ZHOU, Z.H.; DU, A.Q.; HUANG, Z.M. Studies on the flavonol constituents of Abelmoschus manihot $\mathrm{L}$. Chin. J. Nat. Med., v.2, p.91-92, 2004.

YING, X.X.; WANG, R.X.; XU, J.; ZHANG, W.J.; LI, H.B.; ZHANG, C.S.; LI, F.M. HPLC determination of eight polyphenols in the leaves of Crataegus pinnatifida Bge. var major. J. Chromatogr. Sci., v.47, p.201-205, 2009.

ZHANG, P.C.; XU, S.X. Chemical constituents from the leaves of Crataegus pinnatifida Bge. var major N E Br. Acta Pharm. Sinic., v.36, p.754, 2001.

Received for publication on $18^{\text {th }}$ January 2013 Accepted for publication on $27^{\text {th }}$ May 2013 